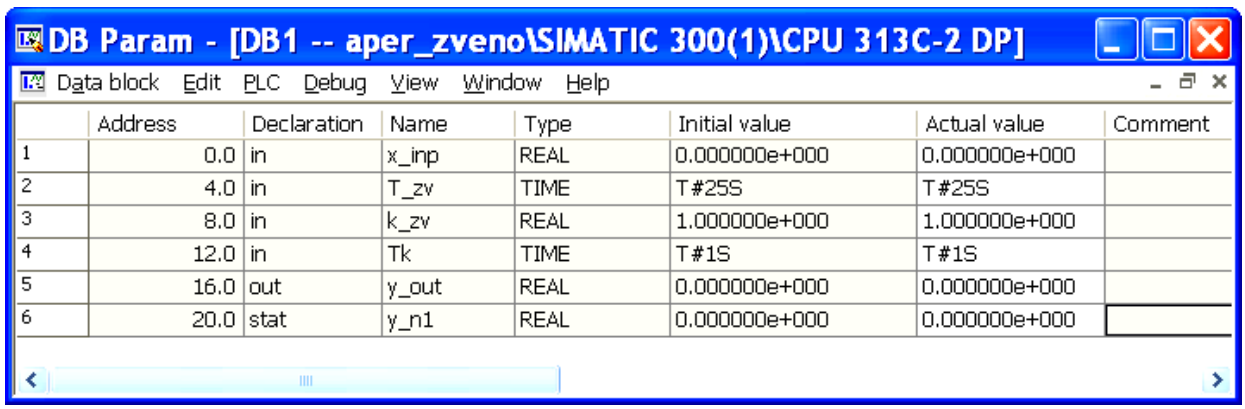

Рис. 3 Вид блока данных DB1

В блоке данных DB1 хранятся входные, выходные и статические переменные функционального блока FB1 в тактах между вычислениями.

Для проверки работоспособности вновь созданного динамического звена следует загрузить проект “ареr_zveno” в контроллер S7-313C-2DP и наблюдать за изменениями выходного аналогового сигнала модуля SM334 при скачкообразном изменении входного. Как известно, в момент времени $t=T_{z v}$ значение на выходе $y(t)=0,63 k_{z v} x(t)$.

Выводы: данный учебный пример показывает, как использовать теоретические знания по цифровым системам управления на практике при программировании реальных контроллеров. Аналогично могут создаваться и более сложные динамические звенья, в том числе и ПИД - регуляторы, рекуррентные зависимости для которых можно найти в [2].

Литература:

1. SIMATIC S7-SCL V5.1 для S7-300/S7-400 Руководство. Редакция 09/2000 A5E00059543-0. Siemens AG 2000. $-336 \mathrm{c}$.

2. Изерман Р. Цифровые системы управления: Пер. с англ. - М.: Мир, 1984. - 541 с.

\title{
ПОБУДОВА АЛГОРИТМУ РЕГУЛЮВАННЯ ХОЛОДОПРОДУКТИВНІСТЮ МУЛЬТИКОМПРЕСОРНОї ХОЛОДИЛЬНӦ̈ МАШИНИ
}

\author{
Заволінковська В. В., Гончаренко О. О. \\ Одеська національна академія харчових технологій
}

Анотація: В даній статті розглядається принцип побудови алгоритму регулювання холодопродуктивністю мультикомпресорної холодильної установки на теорії нечітких множин и нечіткої логіки.

Annotation: In this article the principle of algorithm development regulation multykompresornoyi cooling capacity of the refrigeration unit on the theory of fuzzy sets and fuzzy logic.

Ключові слова: нечіткий регулятор, алгоритм Сугено, АСР мультикомпресорної холодильної установки.

Дослідження, про які піде річ в статті, відносяться до області енергозберігаючих технологій і обладнання. На сьогоднішній день економія енергоресурсів і підвищення ефективності виробництва є одним із найпріоритетніших напрямків розвитку. Вирішенню цієї проблеми в значній мірі допомагає підвищення якості регулювання технологічних процесів в реальних умовах експлуатації.

Регулювання холодопродуктивністю мультикомпресорної холодильної установки характеризуються значними зв'язками між окремими елементами, великою кількістю зовнішніх і внутрішніх впливів, частина з яких недоступна 
для контролю, і високими вимогами до величини припустимих відхилень регулюючих параметрів від заданих значень цих параметрів. Значна частина відмов роботи технологічного обладнання пов'язана 3 приладами контролю, системами захисту і регулювання.

На сьогоднішній день статистика показує, що існує значна частина відмов, поломок автоматичних систем регулювання (АСР), і пов'язано це 3 погіршенням якості регулювання через зміну параметрів у системі. Тому доцільно застосовувати нові підходи при проектуванні АСР. Одним з найефективніших засобів підвищення стійкості роботи та якості регулювання автоматичних систем є використання регуляторів на базі нечіткої логіки.

Створення нечіткої системи регулювання складається з ряду етапів. Розглянемо їх.

Етап 1. Вибір бажаної характеристики перехідного процесу. Як приклад прийнята траєкторія АСР із ПІрегулятором й об'єктом першого порядку із запізнюванням.

Етап 2. Побудова нечіткого алгоритму керування на базі алгоритму Сугено. В системі даного типу база знань будується 3 правил, що мають вид: «Якщзо $x_{1}=$ низький $і x_{2}=$ середній, то $y=a_{0}+a_{1} * x_{1}+a_{2} * x_{2}$ ».

Етап3.Нечіткий висновок по алгоритму Такаги-Сугено виконується по нечіткій базі знань:

$$
\mathrm{U}_{p=1}^{x_{J}}\left(\cap_{i=1}^{n}=a_{j, j p} \text { з вагою } \mathcal{W}_{j p}\right) \rightarrow \underset{\mathrm{J}=1, \mathrm{~m}}{=b_{j, 0}}+b_{j, 1} * x_{1}+b_{j, 2} * x_{2}+\ldots+b_{j, n} * x_{n},
$$

Таким чином правила в базі Сугено являються свого роду перемикачами 3 одного лінійного закону «ВИХІД-ВХІД» на інший, теж лінійний.

Етап 4. Дефазифікація проводиться за методом центроїда (центру ваги).

Використання алгоритмів керування 3 нечіткою логікою зумовлена розкладанням безперервного керуючого сигналу на вектор 3 трьох елементів: двох дискретних (на опорні компресори) і один безперервний (на компресор 3 неперервним регулюванням холодопродуктивності):

$$
\begin{gathered}
U_{K 1}^{c}=U_{K 1}^{c}-U_{K 2}^{d}-U_{K 3}^{d}, \\
U_{K 2}^{d}=\left\{\begin{array}{rl}
1, & U_{y}^{c}>1 \\
0, & U_{y}^{c}<1
\end{array} \quad U_{K 3}^{d}=\left\{\begin{array}{rr}
1, & U_{y}^{c}>2 \\
0, & U_{y}^{c}<2
\end{array}\right.\right.
\end{gathered}
$$

Виходячи $з$ цього система повинна мати підвищену стійкість і зменшене перерегулювання для уникнення зайвих пусків опорних компресорів, при збереженні необхідної швидкості. Тобто необхідна система управління, яка в залежності від помилки регулювання буде використовувати різні закони регулювання і при цьому при переході від одного закону до іншого не повинно бути стрибкових впливів, які негативно впливають на вихідний сигнал. Побудувати таку систему можна за допомогою алгоритмів нечіткої логіки.

На першому етапі обирається лінгвістична змінна для відхилення температури в холодильній камері від заданої з такими параметрами:

-назва: «dT»

-універсальна множина U[-45;10], на якій буде відбуватися стеження за відхиленням температури від заданої

- терм множина T, яка складається 3 таких термів $\{B N, L N, N Z, N u L L\}$, які зображені на рисунку 1.

Трикутник LN-середне негативне відхилення,

трикутник NZ- мале відхилення,

трикутник NuLL- відхилення біля нуля чи додатнє.

Терм BN - трапеціевидна функія приналежності, яка відповідає приналежності сигналу до дуже великих відхилень, які мають місце лише при пуску системи, чи довгому простої, тому в правилах приналежності цьому терму виводять систему на максимальну потужність.

Для опису вихідної лінгвістичної змінної задамося системою типу Сугено. 


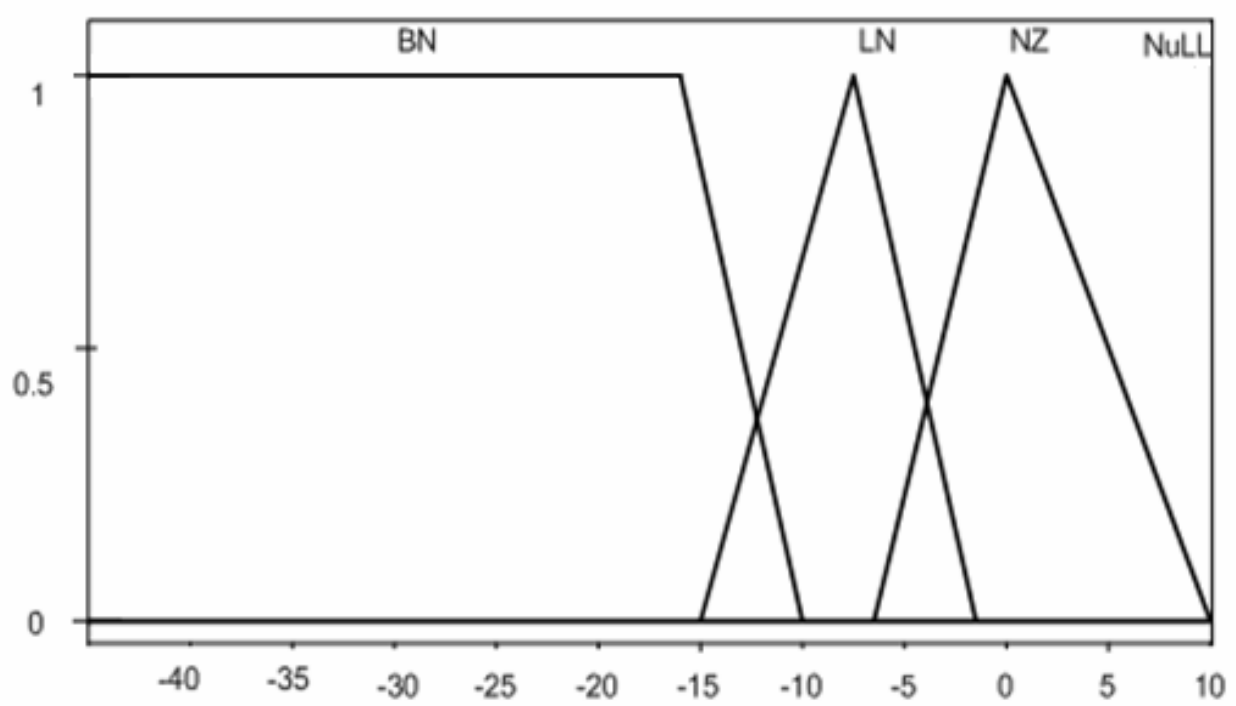

Рис.1 - Функції приналежності до нечітких множин

У вихідній змінній описані наступні терми:

- Min - мінімальний вихідний сигнал (0), з вектором $[0 ; 0 ; 0 ; 0]$;

- Мах- максимальний вихідний сигнал (1), з вектором [0;0;0;1];

- High- сигнал від регулятора 3 високою швидкодією (П-регулятор), 3 вектором [0; 0; $1 ; 0]$;

- Low - сигнал від регулятора 3 підвищеною стійкістю та точністю регулювання (ПІрегулятор), $з$ вектором $[0 ; 1 ; 0 ; 0]$.

Вирішено використовувати сигнал на вході від класичних (П- та ПІ) регуляторів для наочності роботи схеми, та полегшення етапу знаходження оптимальних коефіцієнтів. В кінцевому варіанті АСР всю генерацію керуючого сигналу буде реалізовано в блоці нечіткого регулятора.

Для сигналів П- та ПІ-регуляторів в систему введемо ще дві вхідних змінних: P-reg та PI-reg відповідно.

Правила істинності для даної структури мають наступний вигляд:

1. Якщо $\mathrm{dT}=\mathrm{BN}$ то output $\sim \operatorname{Max} 3$ вагою 1 ;

2. Якщо $\mathrm{dT}=\mathrm{LN}$ то output $1 \sim$ High 3 вагою 1 ;

3. Якщо dT=NZ то output $1 \sim$ Low 3 вагою 1 ;

4. Якщо dT=BN то output $1 \sim$ NuLL 3 вагою 0.5 . 

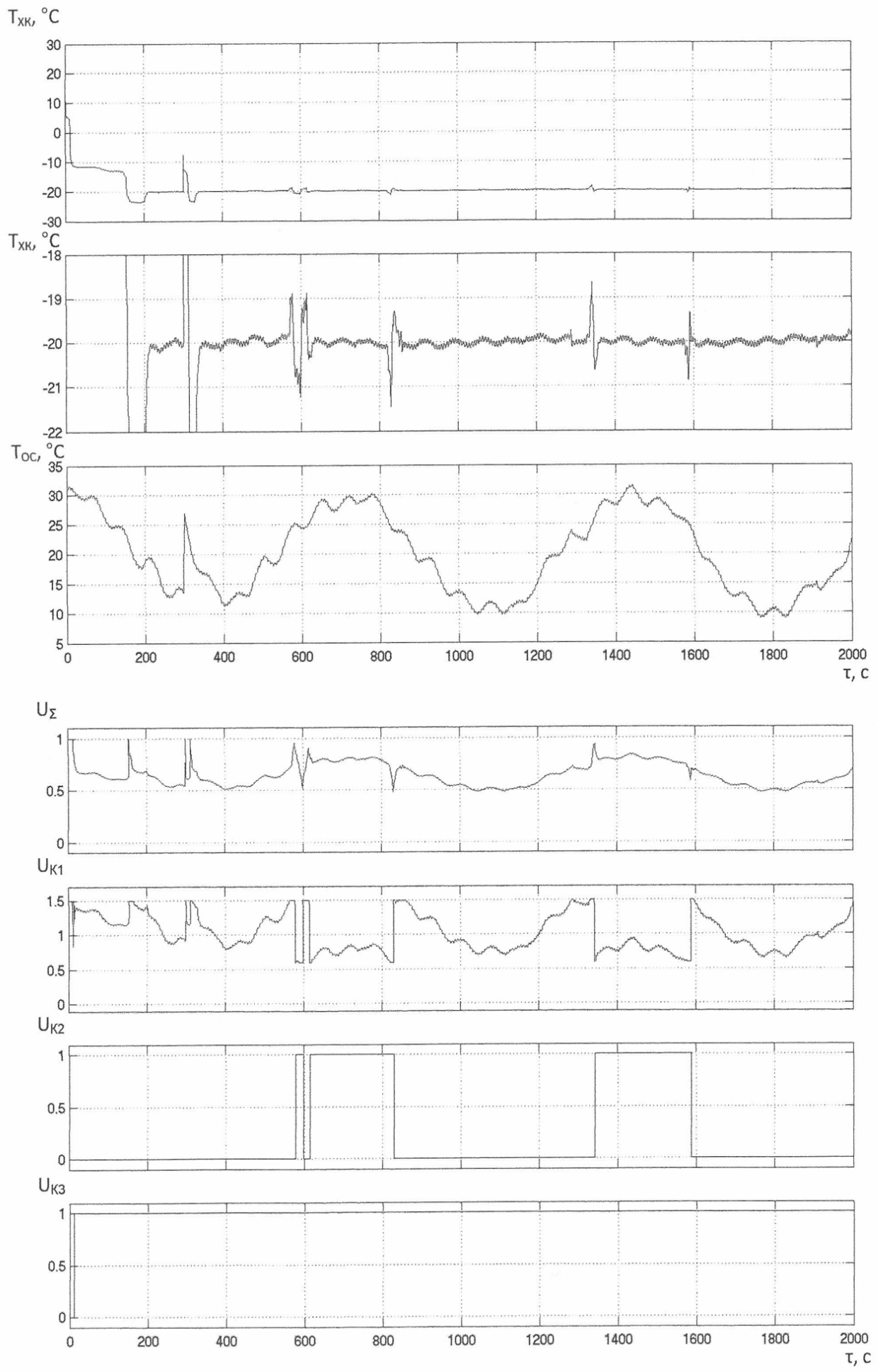

Рис.2 - Перехідні процеси у системі з АСР на нечіткій логіці 
Як видно з результатів моделювання характеристики системи поліпшились. Підвищилась стійкість системи до стрибкоподібних збурень по температурі навколишнього середовища, а також до високочастотних збурень. Кількість включень компресорів 3 дискретним керуванням знизилась до чотирьох за 2000 одиниць часу, які відповідають щонайменше 1.5 добам. Це у 240 разів менше ніж при дискретному керуванні та у 8 разів менше ніж пр. керуванні за допомогою класичного ПІ-регулятора.

Завдяки впровадженню в систему регулятора на нечіткій логіці, існує можливість під час експлуатації змінювати вагу правил та проводити допоміжні правила, що можуть бути пов'язані з іншими параметрами холодильного циклу (кипіння, конденсації, рівня холодоагентів в теплообмінних апаратах), та правила, що можуть бути пов'язані з експлуатаційними особливостями (тип роботи в залежності від часу доби, чи пори року, енергозберігаючий режим, тощо), допоміжні реакції на деякі події.

Висновки. Таким чином, регулювання холодопродуктивністю мультикомпресорної холодильної установки на теорії нечітких множин и нечіткої логіки забезпечує:

- при зміні параметрів об’ єкта в 3 рази кращі показники якості (в порівнянні з класичним ПІ-регулятором): менше значення перерегулювання (на $32 \%$ ) та часу регулювання (на $185 \mathrm{c}$ );

- вибір оптимального режиму роботи;

- зміну температури та підтримання заданої ;

- зменшення витрат електроенергії на 20-40\%.

\title{
Література
}

1. Заде Л. Понятие лингвистической переменной и его применение для принятия приближённых решений. М.: Мир, 1976. 165 с.

2. Беллман Р., Заде Л. Принятие решений в расплывчатых условиях // Вопросы анализа и процедуры принятия решений: Сб. статей / Пер. с англ.; Под ред. И.Ф.Шахнова. М., 1976. С.172-215.

3. Обработка нечеткой информации в системах принятия решений / А.Н.Борисов, А.В.Алексеев,

4. .В.Меркурьева и др. М.: Радио и связь, 1989. 305 с.

5. Кофман А. Введение в теорию нечетких множеств. М.: Радио и связь, 1982. 432 с.

УДК 631.365 .2

\section{АВТОМАТИЗАЦІЯ ПРОЦЕСУ СУШКИ ЗЕРНА. ДОЦІЛЬНІСТЬ, ОСОБЛИВОСТІ ТА ЕТАПИ ВПРОВАДЖЕННЯ}

\author{
Зубренко К.С., \\ Одеська національна академія харчових технологій, м. Одеса
}

\begin{abstract}
Анотація: Дана стаття присвячена ознайомленню з процесом автоматизації сушки зерна. Також в даній статі розглянуті основні проблеми при впровадженні процесу та способи їх вирішення .

Annotation: This article is devoted to familiarization of the automation process of drying grain. There are also reviewed the main problems of implementation process and it's solving methods.

Ключові слова: автоматизація , зерносушарки, сушка, зерно.

Одним з головних завдань агропромислового комплексу є досягнення стійкого зростання сільськогосподарського виробництва. Мало виростити і зібрати врожай, його потрібно ще й якісно зберігати. Продукти потрібно готувати до закладання на зберігання, забезпечувати певні умови зберігання та контролю за цим процесом. Для цього необхідна технічна база: сховища, оснащені необхідним обладнанням для контролю процесу зберігання, обладнання для підготовки до зберігання, очисні комплекси, сушарки. Застосування цієї технічної бази раціональніше автоматизувати. Так, автоматизація на етапі сушіння рослинної сировини дозволить уникнути збитків, зменшити вплив людського фактора, уникнути великих втрат, що наносяться аваріями на виробництві. Завдання повної
\end{abstract}

